\section{Child Maltreatment Data in Canada}

Dear Editor:

We read with interest Dr. Afifi's commentary that described child maltreatment as an understudied Canadian public health problem and suggested ways that necessary data could be collected. ${ }^{1}$ Part of Dr. Afifi's argument concerned use of the Canadian Community Health Survey (CCHS) as a vehicle for collecting data about the prevalence of childhood maltreatment in Canada. She noted that a final decision about inclusion of childhood maltreatment questions in a future CCHS had not been made. We offer this update: the 2012 CCHS, which focuses on mental health, includes six questions about childhood maltreatment and one question about childhood involvement with child protective services (e.g., Children's Aid Society). These questions, based on the Childhood Experiences of Violence Questionnaire, will assess the childhood experiences (before age 16 years) of CCHS respondents aged 18 years and older in these areas: corporal punishment and physical abuse (3 questions), sexual abuse (2 questions), and exposure to intimate partner violence (1 question). ${ }^{2}$

Data from this survey will greatly advance understanding of Canadians' mental health and social correlates of childhood maltreatment. The CCHS 2012 is in the field now, and data are expected to be released in mid 2013. Data will be available through Statistics Canada's research data centres.

In addition, data from the 2008 Canadian Incidence Study of Reported Child Abuse and Neglect, which is a cross-Canada study of child protection agencies' child maltreatment investigations, are available to researchers and student researchers for secondary analyses (child.maltreatment@phac-aspc.gc.ca). ${ }^{3}$

We realize that these developments will not address all of Dr. Afifi's recommendations. Incidence of child maltreatment unreported to authorities is still unresearched at a national level, as are maltreatment prevalence data from Canadian children and adolescents, as well as data regarding maltreatment types such as neglect and emotional/psychological abuse. In keeping with Dr. Afifi's suggestions, we will continue to work to address these data gaps.

Wendy Hovdestad, PhD, Senior Research Analyst

\section{Lil Tonmyr, MSW, PhD, Senior Researcher}

Injury and Child Maltreatment Section, Health Surveillance and Epidemiology Division, Public Health Agency of Canada, Ottawa, ON

\section{REFERENCES}

1. Afifi TO. Child maltreatment in Canada: An understudied public health problem. Can J Public Health 2011;102:459-61.

2. Walsh CA, MacMillan HL, Trocmé N, Jamieson E, Boyle MH. Measurement of victimization in adolescence: Development and validation of the Childhood Experiences of Violence Questionnaire. Child Abuse and Neglect 2008;32:103757.

3. Public Health Agency of Canada. Canadian Incidence Study of Reported Child Abuse and Neglect - 2008: Major Findings. Ottawa, ON: PHAC, 2010.

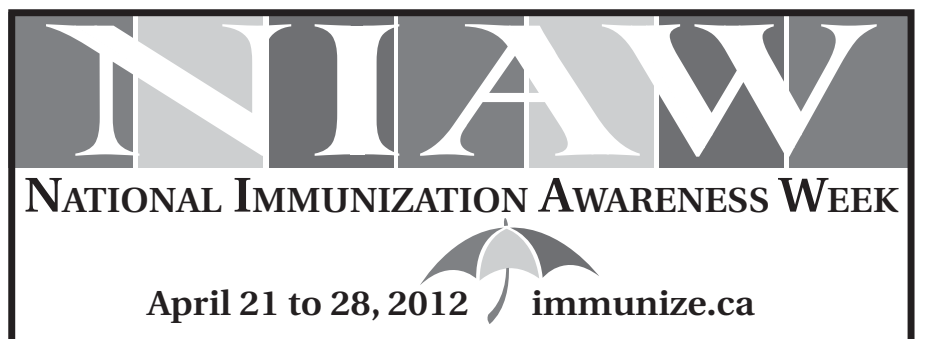

\section{Protect your world. Get immunized.}
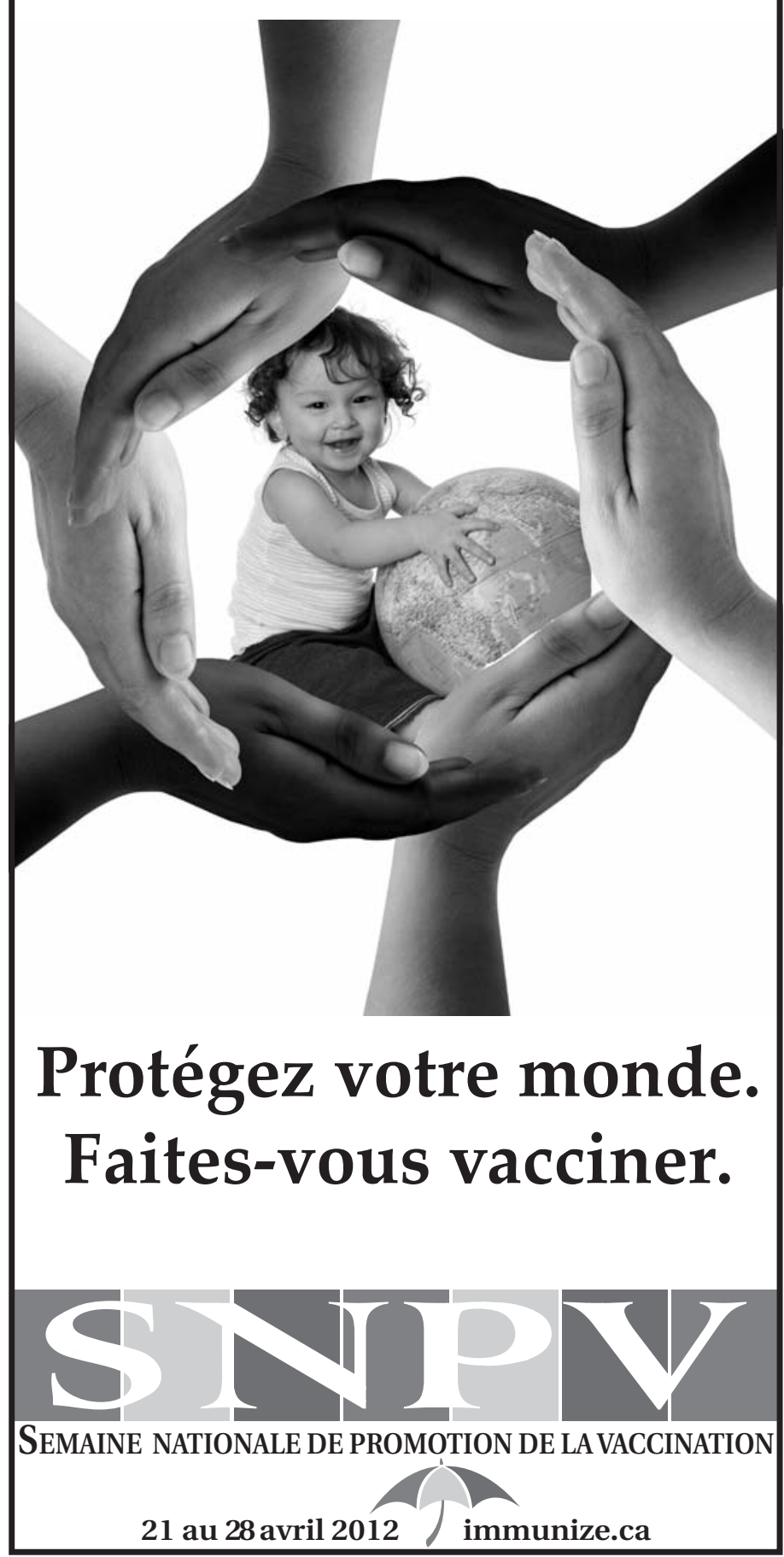